CARDIOVASCULAR MEDICINE

\title{
Influence of diabetes mellitus on coronary collateral flow: an answer to an old controversy
}

\author{
R Zbinden, S Zbinden, M Billinger, S Windecker, B Meier, C Seiler
}

Heart 2005;91:1289-1293. doi: 10.1136/hrt.2004.041236

See end of article for authors' affiliations

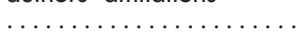

Correspondence to: Professor Christian Seiler, University Hospital Bern, $\mathrm{CH}-3010$ Bern, Switzerland; christian. seiler@insel.ch

Accepted

26 November 2004

\begin{abstract}
Objectives: To determine the influence of diabetes mellitus on coronary collateral flow by accurate means of collateral flow measurement in a large population with variable degrees of coronary artery disease. Methods: 200 patients (mean (SD) age 64 (9) years; 100 diabetic and 100 non-diabetic) were enrolled in the study. Coronary collateral flow was assessed in 174 stenotic and in 26 angiographically normal vessels with a pressure guidewire $(n=131)$, Doppler guidewire $(n=36)$, or both $(n=33)$ to calculate pressure or flow velocity derived collateral flow index (CFI). Diabetic patients were perfectly matched with a non-diabetic control group for clinical, haemodynamic, and angiographic parameters.

Results: CFI did not differ between the diabetic and the non-diabetic patients $(0.21(0.12) v 0.19(0.13)$, not significant). Likewise, CFI did not differ when only angiographically normal vessels $(0.20(0.09) v 0.15$ $(0.08)$, not significant) or chronic total coronary occlusions $(0.30(0.14) \vee 0.30(0.17)$, not significant) were compared. Fewer patients in the diabetic group tended to have angina pectoris during the one minute vessel occlusion (60 diabetic $v 69$ non-diabetic patients, $p=0.15$ ).

Conclusion: Quantitatively measured coronary CFI did not differ between diabetic and non-diabetic patients with stable coronary artery disease.
\end{abstract}

$\mathrm{T}$ he coronary collateral circulation is an alternative source of blood supply to myocardium supplied by a stenotic or occluded coronary artery. A well developed coronary collateral circulation has a favourable impact on the prognosis of patients with coronary artery disease (CAD). ${ }^{12}$ So far, only a few pathogenetic factors have been consistently described as influencing the development of coronary collateral vessels, namely the severity of coronary artery stenosis $^{3}$ and the duration of myocardial ischaemic symptoms. ${ }^{4}$

Endothelial dysfunction, structural changes of the microcirculation, and the negative influence on the development and prognosis of CAD are well established features of patients with diabetes mellitus (DM $)^{5-7}$ On the other hand, the influence of DM on coronary collateral growth has been controversial. One clinical study by Abaci et $a l^{8}$ reported reduced coronary collateral development in patients with DM compared with non-diabetic patients; Melidonis et al ${ }^{9}$ reported exactly the contrary. These conflicting reports were based on angiographic assessment of coronary collaterals, which correlates only poorly with quantitative parameters of collateral function. ${ }^{10}$ Recent developments in microsensor technology have made it possible to study collateral perfusion pressure and flow velocity and to calculate pressure and Doppler derived collateral flow indices, which correlate well with other means of perfusion measurement such as single photon emission computed tomography. ${ }^{11}$ A recent study by Werner et al, ${ }^{12}$ who used the mentioned invasive method, found no overall difference in coronary collateral flow between diabetic and non-diabetic patients. The major limitations of their study were the relatively small number of patients examined and the restriction to patients with chronic total coronary occlusion.

The purpose of our study was to determine the influence of DM on coronary collateral flow index (CFI) by means of accurate collateral flow measurement in a large population with variable degrees of CAD. Possible confounding factors were eliminated by matching patients with DM to a nondiabetic control group for age, sex, percentage diameter coronary stenosis, serum lipids, and cardiovascular risk factors.

\section{METHODS \\ Patients}

Two hundred patients (age 64 (9) years; 156 men and 44 women) referred for diagnostic coronary angiography were enrolled in the study. Twenty six patients had angiographically totally normal coronary arteries and 174 patients had one to three vessel CAD. Coronary CFI was assessed in 174 stenotic and in 26 angiographically normal vessels (that is, with no wall irregularities and no stenotic lesions). One hundred patients had DM and 100 patients served as nondiabetic control group. Each diabetic patient was matched with a non-diabetic control patient for sex, age, serum lipids, percentage diameter stenosis of the vessel undergoing CFI measurement, and cardiovascular risk factors.

Patients with acute coronary syndrome, severe valvar heart disease, previous coronary artery bypass surgery, previous myocardial infarction in the area undergoing CFI measurement, or severe hepatic or renal insufficiency were excluded. The patients in this study have been described in part elsewhere. ${ }^{3}$ These studies were approved by the local ethics committee and the patients gave written informed consent to participate. For ethical concerns about inflating a balloon in an angiographically normal vessel we refer to Wustmann et al. ${ }^{13}$

\section{Coronary angiography}

All patients underwent left heart catheterisation, including biplane left ventricular angiography and coronary angiography for diagnostic purposes. Coronary artery stenoses were assessed quantitatively as the percentage diameter lumen reduction by using the guiding catheter for calibration.

Abbreviations: $C A D$, coronary artery disease; $C F I$, collateral flow index; $\mathrm{CFI}_{p}$, pressure derived collateral flow index; $\mathrm{CFI}_{\mathrm{v}}$, velocity derived collateral flow index; CVP, central venous pressure; DM, diabetes mellitus; $P_{a o}$, mean aortic pressure; $P_{\text {ocd }}$, distal coronary pressure at the end of a one minute balloon occlusion 


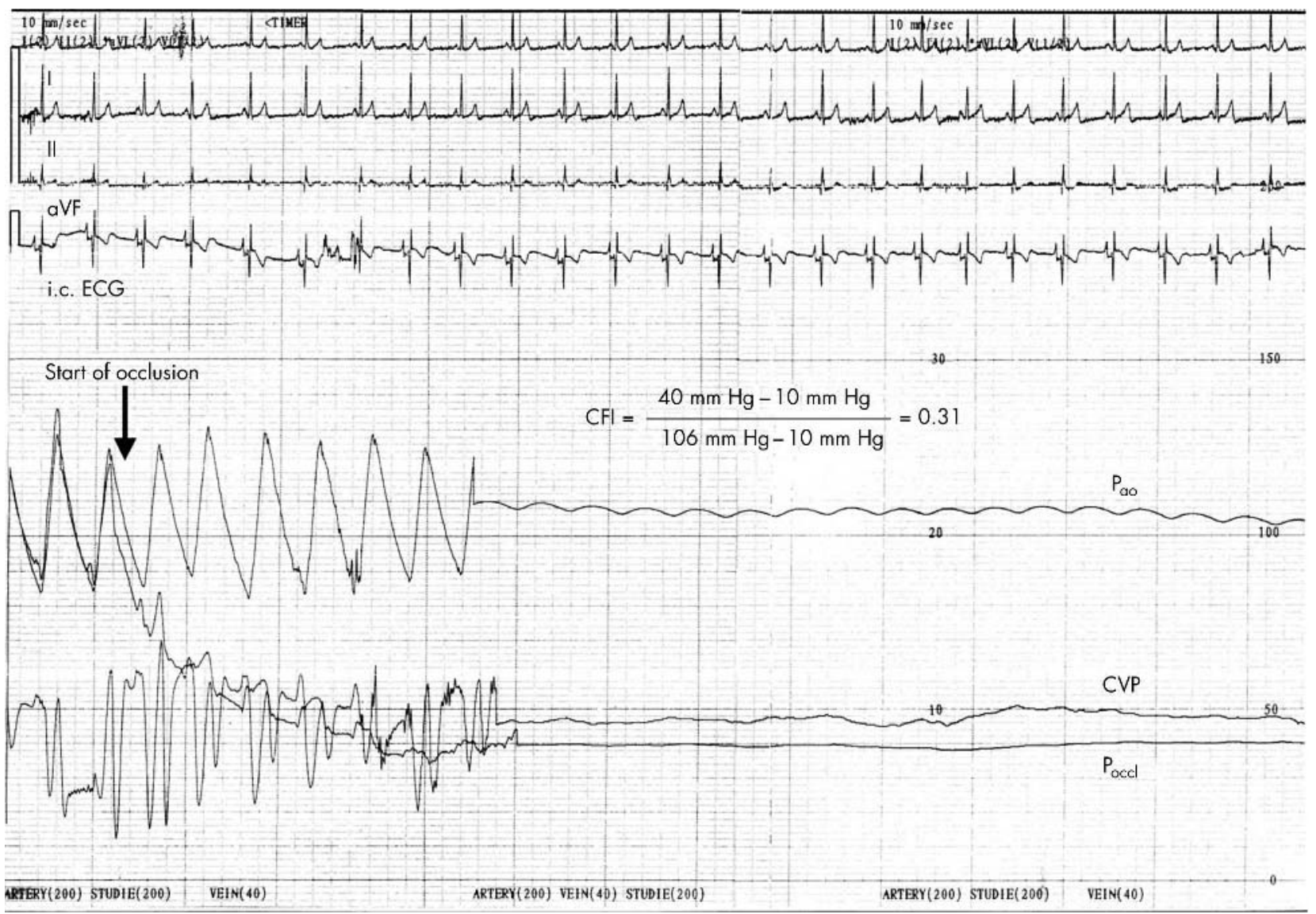

Figure 1 Coronary collateral flow assessment with an intracoronary pressure guidewire in a patient with insulin dependent diabetes mellitus with angiographically normal coronary arteries. Collateral flow index (CFI), expressing collateral flow to the balloon occluded coronary artery relative to normal antegrade flow during vessel patency, is determined from mean aortic pressure $\left(P_{\text {ao }}\right)$, mean coronary pressure during balloon occlusion $\left(P_{\text {occl }}\right)$, and central venous pressure (CVP) (phasic recordings of these pressures obtained during coronary patency are shown at left). After balloon occlusion,

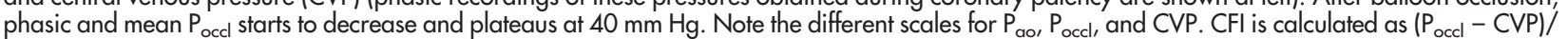
$\left(P_{a o}-C V P\right)$. On the surface lead (I, II, aVF) and on the intracoronary ECG lead recorded through the sensor guidewire, no signs of myocardial ischaemia (ST segment changes) were observed during vessel occlusion when compared with the period before coronary occlusion. Additionally, the patient did not feel any chest pain during the one minute balloon occlusion.

\section{Collateral vessel assessment}

Either a 0.014 inch pressure sensor tipped guidewire, a Doppler guidewire, or both were used during balloon occlusion and percutaneous coronary intervention. The fibreoptic pressure guidewire (WaveWire, Endosonics, Rancho Cordova, California, USA; or PressureWire, Radi Medical Systems, Uppsala, Sweden) was set at zero, calibrated, advanced through the guiding catheter, normalised for aortic pressure at the ostium of the coronary artery, and positioned distal to the stenosis to be dilated or distal to the balloon occlusion in the angiographically normal vessels. Pressure derived CFI ( $\mathrm{CFI}_{\mathrm{p}}$; no unit) was determined by simultaneous measurement of mean aortic pressure $\left(\mathrm{P}_{\mathrm{ao}}\right.$; $\mathrm{mm} \mathrm{Hg}$ ) and of distal coronary pressure at the end of a one minute balloon occlusion ( $\left.\mathrm{P}_{\text {occl }} ; \mathrm{mm} \mathrm{Hg}\right)$. If not measured simultaneously $(\mathrm{n}=77)$, central venous pressure (CVP; $\mathrm{mm} \mathrm{Hg})$ was assumed to be $7 \mathrm{~mm} \mathrm{Hg}(\mathrm{n}=87)$. $\mathrm{CFI}_{\mathrm{p}}$ was calculated as $\left(\mathrm{P}_{\mathrm{occl}}-\mathrm{CVP}\right) /\left(\mathrm{P}_{\mathrm{ao}}-\mathrm{CVP}\right)^{10}$ (fig 1). $\mathrm{CFI}_{\mathrm{p}}$ calculated from an estimated CVP did not differ from those based on a measured CVP $(0.19$ (0.11) $v 0.22$ (0.13), not significant).

Velocity derived CFI ( $\mathrm{CFI}_{\mathrm{v}}$; no unit) was measured $(\mathrm{n}=69)$ with a 0.014 inch Doppler guidewire with a $12 \mathrm{MHz}$ piezoelectric crystal at its tip (FlowWire, Endosonics). $\mathrm{CFI}_{\mathrm{V}}$ was determined as the flow velocity time integral distal to the balloon occluded artery divided by the baseline flow velocity time integral obtained at the same site before balloon occlusion. Bidirectional flow velocity signals were added to obtain the total collateral flow velocity. ${ }^{10}$ In 33 patients pressure and Doppler derived CFI were measured simultaneously and $\mathrm{CFI}_{\mathrm{p}}$ and $\mathrm{CFI}_{\mathrm{v}}$ were averaged to determine CFI. There is a very good correlation between $\mathrm{CFI}_{\mathrm{V}}$ and $\mathrm{CFI}_{\mathrm{p}}{ }^{10}$ and the two methods are interchangeable.

Myocardial ischaemia during balloon occlusion was assessed by the occurrence of angina pectoris and by a simultaneously obtained intracoronary ECG. ST segment changes in the intracoronary ECG were defined as indicative of ischaemia if they were $>0.1 \mathrm{mV}$ during the one minute balloon occlusion.

\section{Statistical analysis}

Data are expressed as mean (SD) for continuous variables and as number (percentage) for categorical variables. For comparison of continuous variables between the two groups, an unpaired Student's $t$ test was used. Categorical variables between the two populations were compared by the $\chi^{2}$ test. Significance was defined as $\mathrm{p}<0.05$.

\section{RESULTS}

With regard to clinical characteristics, the two groups differed significantly only in body mass index only (table 1). 
Table 1 Clinical characteristics

\begin{tabular}{|c|c|c|c|}
\hline & $\begin{array}{l}\text { Diabetic patients } \\
(\mathrm{n}=100)\end{array}$ & $\begin{array}{l}\text { Non-diabetic patients } \\
(n=100)\end{array}$ & p Value \\
\hline Men & $78(78 \%)$ & $78(78 \%)$ & NS \\
\hline Age (years) & $64(9)$ & $64(9)$ & NS \\
\hline Body mass index $\left(\mathrm{kg} / \mathrm{m}^{2}\right)$ & $28.4(3.8)$ & $26.2(3.8)$ & 0.0002 \\
\hline Mean aortic pressure $(\mathrm{mm} \mathrm{Hg})$ & $91(11)$ & $91(14)$ & NS \\
\hline Heart rate (beats/min) & 72 (13) & 70 (13) & NS \\
\hline $\operatorname{LVEF}(\%)$ & $64(11)$ & $63(12)$ & NS \\
\hline LVEDP $(\mathrm{mm} \mathrm{Hg})$ & $12.9(6.5)$ & $12.3(5.0)$ & NS \\
\hline Duration of angina pectoris (months) & $21(42)$ & $20(41)$ & NS \\
\hline Cardiovascular risk factors & & & NS \\
\hline Systemic hypertension & $73(73 \%)$ & $69(69 \%)$ & NS \\
\hline Smoking & $36(36 \%)$ & $38(38 \%)$ & NS \\
\hline Hypercholesterolaemia & $52(52 \%)$ & $54(54 \%)$ & NS \\
\hline Family history of CAD & $31(31 \%)$ & $41(41 \%)$ & NS \\
\hline Cardiovascular medication & & & NS \\
\hline Aspirin & $86(86 \%)$ & $84(84 \%)$ & NS \\
\hline$\beta$ Blockers & $64(64 \%)$ & $69(69 \%)$ & NS \\
\hline Nitrates & $39(39 \%)$ & $37(37 \%)$ & NS \\
\hline Statins & $39(39 \%)$ & $42(42 \%)$ & NS \\
\hline ACE inhibitors & $35(35 \%)$ & $25(25 \%)$ & NS \\
\hline AT II receptor antagonists & $8(8 \%)$ & $4(4 \%)$ & NS \\
\hline Calcium antagonists & $23(23 \%)$ & $15(15 \%)$ & NS \\
\hline Diuretics & $29(29 \%)$ & $20(20 \%)$ & NS \\
\hline Blood chemistry & & & NS \\
\hline Total cholesterol (mmol/l) & $5.3(1.2)$ & $5.3(1.0)$ & NS \\
\hline HDL cholesterol (mmol/l) & $1.1(0.4)$ & $1.2(0.3)$ & NS \\
\hline LDL cholesterol (mmol/I) & $3.2(1.0)$ & $3.4(0.9)$ & NS \\
\hline Total cholesterol:HDL cholesterol & $4.8(1.7)$ & $4.7(1.6)$ & NS \\
\hline Triglycerides (mmol/l) & $2.2(1.7)$ & $2.1(1.7)$ & NS \\
\hline Fasting blood glucose (mmol/l) & $8.9(3.3)$ & $6.0(0.9)$ & $<0.0001$ \\
\hline Haemoglobin Alc (\%) & $7.2(2.4)(n=15)$ & $5.9(0.4)(n=12)$ & 0.05 \\
\hline
\end{tabular}

Data are mean (SD) or number (\%) of CFI measurements.

$A C E$, angiotensin converting enzyme; AT II, angiotensin II; CAD, coronary artery disease; HDL, high density lipoprotein; LDL, low density lipoprotein; LVEDP, left ventricular end diastolic pressure; LVEF, left ventricular ejection fraction; NS, not significant.

Furthermore, fasting glucose and haemoglobin lc differed significantly. Coronary angiographic data were similar in the two groups (table 2).

Figure 1 gives an example of CFI measurement in an insulin dependent diabetic patient with angiographically normal coronary arteries.

CFI did not differ between the diabetic and the non-diabetic groups (fig 2, table 2). Similarly, CFI did not differ when only angiographically normal vessels (fig 3, table 2 ) or chronic total coronary occlusions were compared (fig 4, table 2).

No difference between the two groups concerning ST segment change in the intracoronary ECG was found (table 2).
Fewer patients in the diabetic group tended to have angina pectoris during the one minute vessel occlusion $(\mathrm{p}=0.15)$.

\section{DISCUSSION}

Quantitative means of measuring coronary CFI and careful accounting of cofactors influencing it detect no difference between diabetic and non-diabetic patients. Previous clinical studies of DM and coronary collateral flow have been controversial, possibly because of the use of inaccurate means of assessing coronary collateral flow or because differences in cofactors that influence collateral flow variably in diabetic and non-diabetic patients (serum lipids, severity

Table 2 Coronary angiographic data and collateral flow assessment

\begin{tabular}{|c|c|c|c|}
\hline & $\begin{array}{l}\text { Diabetic patients } \\
(n=100)\end{array}$ & $\begin{array}{l}\text { Non-diabetic } \\
\text { patients }(n=100)\end{array}$ & p Value \\
\hline \multicolumn{4}{|l|}{ Vessel undergoing $\mathrm{CFI}$ measurement } \\
\hline Left anterior descending coronary artery & $39(39 \%)$ & $51(51 \%)$ & NS \\
\hline Left circumflex coronary artery & $29(29 \%)$ & $21(21 \%)$ & NS \\
\hline Right coronary artery & $32(32 \%)$ & $28(28 \%)$ & NS \\
\hline Coronary angiographic data & & & NS \\
\hline Percentage diameter stenosis & $68(320)$ & $68(30)$ & NS \\
\hline Number of vessels diseased & $1.8(0.8)$ & $1.8(0.8)$ & NS \\
\hline Number of stenoses & $3.0(2.0)$ & $2.7(1.9)$ & NS \\
\hline Presence of chronic total coronary occlusion* & $27(27 \%)$ & $21(21 \%)$ & NS \\
\hline Collateral flow assessment & & & NS \\
\hline CFIt & $0.21(0.12)$ & $0.19(0.13)$ & NS \\
\hline CFI in angiographically normal vessels & $0.20(0.09)(n=13)$ & $0.15(0.08)(n=13)$ & NS \\
\hline $\mathrm{CFI}$ in chronic total coronary occlusions & $0.30(0.14)(n=18)$ & $0.30(0.17)(n=18)$ & NS \\
\hline Angina pectoris during balloon occlusion & $60(60 \%)$ & $69(69 \%)$ & 0.15 \\
\hline ST segment elevation in intracoronary ECG $>0.1 \mathrm{mV}$ & $74(74 \%)$ & 79 (79\%) & NS \\
\hline
\end{tabular}

Data are mean (SD) or number (\%) of CFI measurements.

*36 chronic total coronary occlusions were targeted for CFI measurement.

†Average of velocity and pressure derived CFI when measured simultaneously $(n=36)$. 


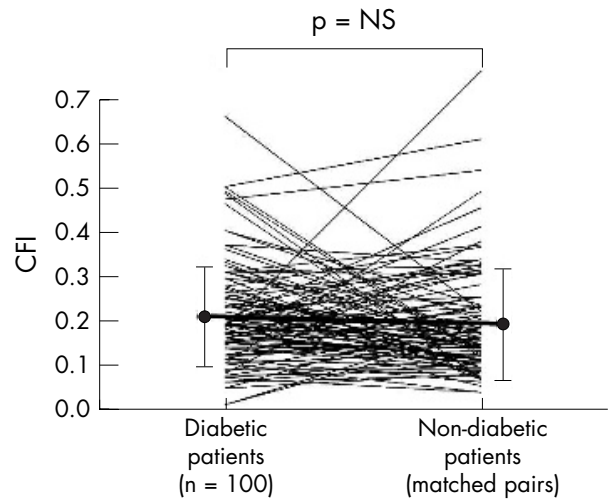

Figure 2 One hundred measurements in 100 diabetic patients are shown on the left and linked to matched control measurements in the non-diabetic group. Additionally, mean (SD) CFI values (vertical axis) are given (filled circles and vertical error lines).

of $\left.\mathrm{CAD}^{14}\right)$ were not accounted for. Additionally, differentiation between angiogenesis and arteriogenesis is important to understand the influence of DM on blood vessel development.

\section{Angiogenesis versus arteriogenesis}

Results from experimental investigations are very consistent concerning the pro-angiogenic effect of DM. This is well reflected by the fact that one of the major complications of DM is blindness caused by stimulated ocular angiogenesis (with the production of leaky capillaries lacking pericytes ${ }^{15}$ ). However, it is important to know that there are different forms of vessel growth: firstly, vasculogenesis (primarily occurring during embryonic development by differentiation of haematopoietic stem cells); secondly, angiogenesis (sprouting of new capillary-like vessels out of existing ones, occurring during embryonic development and under certain conditions in the adult); and thirdly, arteriogenesis (preexisting collateral arterioles are remodelled into arteries by dilatation and by proliferation of smooth muscle cells and endothelial cells with consecutive acquisition of the typical arterial structure). ${ }^{16}$ Collateral artery development is exclusively caused by arteriogenesis, unlike angiogenesis, which is responsible for the known ocular complication of DM. ${ }^{17}$

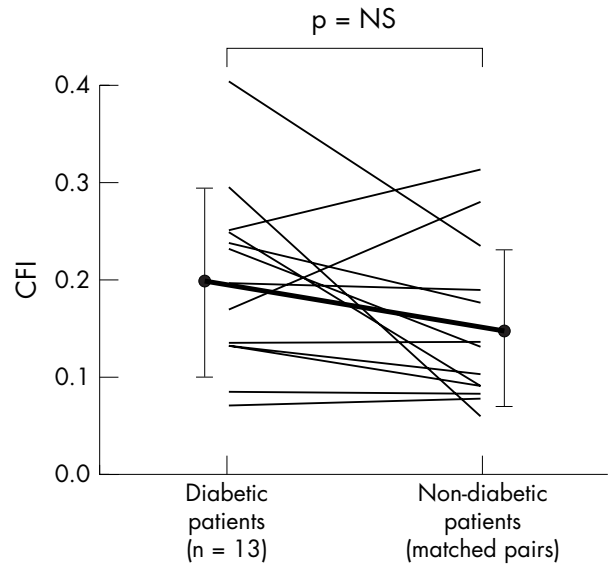

Figure 3 Individual CFI measurements in patients with angiographically normal coronary arteries. Measurements in diabetic patients (mean (SD)) are shown on the left linked to control measurements in the non-diabetic group.

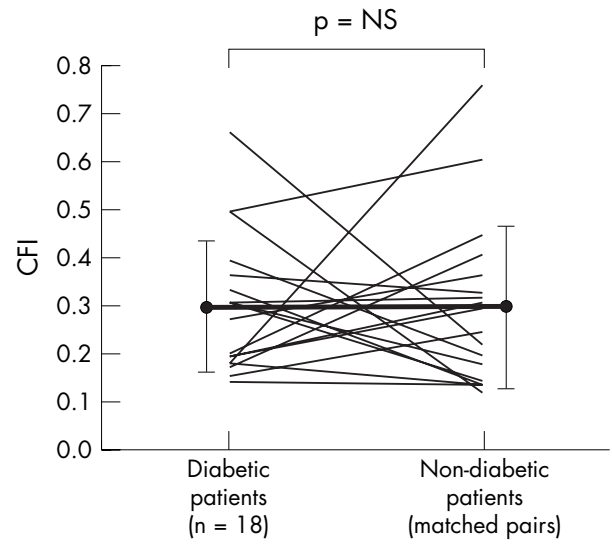

Figure 4 Individual CFI measurements in patients with chronic total coronary occlusion. Measurements in diabetic patients (mean (SD)) are shown on the left and control measurements in matched non-diabetic control patients are shown on the right.

Concerning the effect of DM and increased blood glucose concentrations on arteriogenesis, data from experimental studies are less consistent than investigations on angiogenesis. For example, basic fibroblast growth factor expression (a known proarteriogenic cytokine ${ }^{18}$ ) is increased in the eye, heart, lung, and brain of diabetic rats, ${ }^{19}$ and plasma basic fibroblast growth factor concentrations are increased in male diabetic patients with proteinuria ${ }^{20}$ suggesting a proarteriogenic influence. On the other hand, vascular endothelial growth factor induced chemotaxis of monocytes, which has a key role in arteriogenesis, ${ }^{21}$ is attenuated in patients with DM. ${ }^{22}$ Tamarat et $a l^{23}$ observed reduced collateral flow in a hind limb ischaemia model in diabetic mice after 28 days of ischaemia.

Basic research experiments are certainly accurate models for studying one particular aspect relevant in collateral growth but they do not take into account many cofactors influencing the complex mechanism of arteriogenesis in humans. On the other hand, clinical studies would be the ideal tool to account for all these cofactors but the few studies done on this topic lack a careful selection of the non-diabetic control group and accurate means of collateral flow assessment. Summarised, clinical but also experimental studies have not been ideally designed to study the influence of DM on arteriogenesis (that is, collateral vessel development). The new aspect of the present study that removed the controversy is that we assessed coronary collateral flow with a very sensitive method (especially for low collateral flow values) in a large population with a variable degree of CAD; CFI did not differ between diabetic and non-diabetic patients.

There was a trend $(\mathrm{p}=0.15)$ towards less angina during the one minute balloon occlusion in the diabetic compared with the control group. This is somewhat surprising given the general belief that diabetic patients have less angina pectoris than non-diabetic patients. However, angina pectoris in diabetic patients has not been investigated so far under the condition that diabetic and non-diabetic patients had identical CFI values. The non-significant difference may be caused by the relatively small number of patients having angina pectoris during balloon occlusion $(\mathrm{n}=129)$. On the other hand, the diabetic group tended to have slightly higher CFI (although not significant) than the control group. If angina pectoris did differ greatly (according to common belief) between diabetic and non-diabetic patients, there should have been a significant difference with 200 patients examined. 


\section{Study limitations}

Collateral arteries take several weeks to develop, ${ }^{24}$ and we measured CFI only once in all the study patients. We know from multiple CFI measurements in patients with stable CAD that under stable conditions (for example, no percutaneous coronary intervention or no change in cardiovascular risk factors) CFI remains constant over several weeks. This suggests that under stable conditions a balance between proarteriogenic and antiarteriogenic forces or factors is reached, justifying a single measurement.

Coronary steal is defined as a fall in blood flow towards a certain vascular region in favour of another area during arteriolar vasodilatation. It is an infrequent phenomenon occurring in about $10 \%$ of patients with CAD (especially in patients with well developed collateral vessels). In our study only a few patients had CFI values to allow coronary steal and they were equally distributed between the two groups.

\section{Conclusion}

Our data show that (at a given time point) coronary collateral flow does not differ between diabetic and non-diabetic patients with stable CAD.

\section{ACKNOWLEDGEMENT}

All the signing authors have contributed significantly to the submitted work, and they read and approved the manuscript.

\section{Authors' affiliations}

R Zbinden, S Zbinden, M Billinger, S Windecker, B Meier, C Seiler,

Department of Cardiology, University Hospital Bern, Bern, Switzerland

None of the authors involved in this work have any financial conflicts of interest.

\section{REFERENCES}

1 Hansen J. Coronary collateral circulation: clinical significance on survival in patients with coronary artery occlusion. Am Heart J 1989;117:290-5.

2 Billinger $M$, Kloos P, Eberli FR, et al. Physiologically assessed coronary collateral flow and adverse cardiac ischemic events: a follow-up study in 403 patients with coronary artery disease. J Am Coll Cardiol 2002;40:1545-50.

3 Pohl T, Seiler C, Billinger M, et al. Frequency distribution of collateral flow and factors influencing collateral channel development: functional collateral channel measurement in 450 patients with coronary artery disease. J Am Coll Cardiol 2001;38:1872-8.

4 Fujita M, Nakae I, Kihara Y, et al. Determinants of collateral development in patients with acute myocardial infarction. Clin Cardiol 1999;22:595-9.
5 Schofield I, Mlik R, Izzard A, et al. Vascular structural and functional changes in type 2 diabetes mellitus. Circulation 2002;106:3037-43.

6 Watts GF, O'Brien SF, Silvester W, et al. Impaired endothelium-dependent and independent dilatation of forearm resistance arteries in men with diettreated non-insulin-dependent diabetes: role of dyslipidaemia. Clin Sci 1996:91:567-73.

7 Haffner SM, Lehto S, Rönnemaa T, et al. Mortality from coronary heart disease in subjects with type 2 diabetes and in non-diabetic subjects with and without prior myocardial infarction. N Engl J Med 1998;339:229-34.

8 Abaci A, Oguzhan A, Kahraman S, et al. Effect of DM on formation of coronary collateral vessels. Circulation 1999;99:2239-42.

9 Melidonis A, Tournis S, Kouvaras G, et al. Comparison of coronary collateral circulation in diabetic and non-diabetic patients suffering from coronary artery disease. Clin Cardiol 1999:22:465-71.

10 Seiler C, Fleisch M, Garachemani A, et al. Coronary collateral quantitation in patients with coronary artery disease using intravascular flow velocity or pressure measurements. J Am Coll Cardiol 1998;32:1272-9.

11 Matsuo H, Watanabe S, Kadosaki T, et al. Validation of collateral fractional flow reserve by myocardial perfusion imaging. Circulation 2002;105:1060-5.

12 Werner G, Richartz B, Heinke S, et al. Impaired acute collateral recruitment as a possible mechanism for increased cardiac adverse events in patients with diabetes mellitus. Eur Heart J 2003;24:1134-42.

13 Wustmann K, Zbinden S, Windecker S, et al. Is there functional collateral flow during vascular occlusion in angiographically normal coronary arteries? Circulation 2003;107:2213-20.

14 Freedman DS, Gruchow HW, Bamrah VS, et al. Diabetes mellitus and arteriographically-documented coronary artery disease. J Clin Epidemiol 1988:41:659-68.

15 Rand RI. Recent advances in diabetic retinopathy. Am J Med $1981 ; 70: 595-602$.

16 Carmeliet P. Mechanisms of angiogenesis and arteriogenesis. Nat Med 2000:6:389-95.

17 Ito WD, Arras M, Scholz D, et al. Angiogenesis but not collateral growth is associated with ischemia after femoral artery occlusion. Am J Physiol 1997;273: H1255-65

18 Yang HT, Deschenes MR, Ogilvie RW, et al. Basic fibroblast growth factor increases collateral blood flow in rats with femoral arterial ligation. Circ Res 1996;79:62-9.

19 Karpen CW, Spanheimer RG, Randolph AL, et al. Tissue-specific regulation of basic fibroblast growth factor mRNA levels by diabetes. Diabetes 1992;41:222-6.

20 Zimering MB, Eng J. Increased basic fibroblast growth factor-like substance in plasma from a subset of middle-aged or elderly male diabetic patients with microalbuminuria or proteinuria. J Clin Endocrinol Metab 1996;81:4446-52.

21 Heil M, Ziegelhoeffer T, Pipp F, et al. Blood monocyte concentration is critical for the enhancement of collateral artery growth (arteriogenesis). Am J Physiol Heart Circ Physiol 2002;3:3.

22 Waltenberger J, Lange J, Kranz A. Vascular endothelial growth factorinduced chemotaxis of monocytes is attenuated in patients with diabetes mellitus: a potential predictor for the individual capacity to develop collaterals. Circulation 2000;102:185-90.

23 Tamarat R, Silvestre JS, Huijberts $M$, et al. Blockade of advanced glycation end-product formation restores ischemia-induced angiogenesis in diabetic mice. Proc Natl Adad Sci USA 2003;100:8555-60.

24 Schaper W, Schaper J. Collateral circulation. Norwell: Kluwer Academic Publishers, 1993.

\section{bmjupdates+}

bmjupdates+ is a unique and free alerting service, designed to keep you up to date with the medical literature that is truly important to your practice.

bmjupdates+ will alert you to important new research and will provide you with the best new evidence concerning important advances in health care, tailored to your medical interests and time demands.

Where does the information come from?

bmiupdates+ applies an expert critical appraisal filter to over 100 top medical journals A panel of over 2000 physicians find the few 'must read' studies for each area of clinical interest

Sign up to receive your tailored email alerts, searching access and more...

www.bmjupdates.com 